\title{
Presentación del dossier: "Sensibilidades políticas en coyunturas de crisis y cambio. Propuestas y casos sobre el siglo XIX argentino"
}

\author{
Valentina Ayrolo \\ CONICET/Instituto de Humanidades y Ciencias \\ Sociales-Centro de Estudios Históricos-Facultad de \\ Humanidades-Universidad Nacional de Mar del Plata, \\ Argentina \\ Ana Laura Lanteri \\ CONICET/Instituto de Humanidades y Ciencias \\ Sociales-Centro de Estudios Históricos-Facultad de \\ Humanidades-Universidad Nacional de Mar del Plata, \\ Argentina
}

Cita sugerida: Ayrolo, V. y Lanteri, A. L. (2020). Presentación

del dossier: "Sensibilidades políticas en coyunturas de crisis y

cambio. Propuestas y casos sobre el siglo XIX argentino”.

Anuario del Instituto de Historia Argentina, 20(2), e120.

https://doi.org/10.24215/2314257Xe120

Desde hace algunas décadas el estudio de la historia política argentina del siglo XIX se encuentra en constante desarrollo y renovación. En este marco, para el presente dossier convocamos a reconocidxs investigadorxs con el propósito de que aportaran desde sus estudios a la reflexión sobre coyunturas particulares de crisis y cambio a lo largo del siglo, en clave de sensibilidades políticas. Desde la óptica de variados actores y problemáticas se hacen presentes aquí la guerra de Independencia, la convivencia del federalismo y el unitarismo en el espacio de las provincias durante los años 1830, la construcción de un nuevo orden con posterioridad a Caseros en la "Confederación”, y, finalmente, el clima de la elección y asunción presidencial de Julio A. Roca en el fin de siglo.

Los artículos reunidos nos invitan a conocer e indagar las formas y los sentidos en que, en momentos de inestabilidad, las decisiones de lxs actorxs se apoyaron en sensibilidades o las (re)configuraron a los fines de orientar conductas sociopolíticas. En efecto, plantean un repertorio de prácticas, estrategias y 
percepciones que se ensayaron como respuestas posibles a los nuevos desafíos de las coyunturas críticas. Algunas novedosas y otras con mayor raigambre confluyeron en un sustrato emocional que posibilitó, por ejemplo, la movilización, la negociación de la obediencia y la legitimación de liderazgos, la creación de asociaciones y la escenificación del poder.

En este sentido, lxs lectorxs podrán apreciar las formulaciones conceptuales por las que optaron lxs autorxs, pero interesa destacar que Sara Mata, Fabián Herrero y Ana Romero revelan la potencialidad analítica del intercambio que la Historia Política mantiene con la Sociología y la Antropología política, para vincular las representaciones y las prácticas. Al mismo tiempo Silvia Dócola nos advierte sobre la relevancia de la Arquitectura -y por ende lo productivo de fortalecer este diálogo interdisciplinar-, para indagar la política, considerando las edificaciones como operadoras de cambios sobre los comportamientos y la legitimación del poder.

Los artículos enriquecen el conocimiento sobre distintas coyunturas de cambio del siglo XIX, enfatizando sus alcances y sus límites. Desde un atrayente abordaje de las empresas arquitectónicas que emprendió Justo José de Urquiza, Dócola argumenta que la proyección de las instituciones y áreas públicas de la ciudad capital de Paraná y de la residencia privada en Concepción del Uruguay se vertebró en disímiles sensibilidades arquitectónicas, pero tuvo la intención común de vigorizar a la "Confederación" en el plano interno e internacional. De esta manera brinda nuevas perspectivas sobre el liderazgo de Urquiza y la materialización política de la "Confederación". El resto de los artículos revisan con elocuencia supuestos instalados en la historiografía, y brindan un cuadro más complejo sobre las experiencias que estudian en particular, así como acerca de la década revolucionaria, el proceso político entrerriano y el "orden conservador" en general.

Sara Mata revisa el poder indiscutido de Martín Miguel de Güemes y la "lealtad inquebrantable" de sus escuadrones de gauchos. Cuestiona la idea de que él fue el único artífice de la insurrección y movilización haciendo foco en las adhesiones y desafíos que enfrentó su autoridad. Para ello, restituye el papel clave de los liderazgos militares intermedios en dicha movilización y las estrategias de Güemes frente a estos y sus milicias. De igual modo, refiere a las disputas calibradas sobre proyectos políticos, contiendas territoriales y rivalidades personales que perfilaron su asesinato en 1821 .

Por su lado, Fabián Herrero revierte la óptica sobre la "provisionalidad y debilidad" con que fueron caracterizados distintos gobiernos en Entre Ríos en las primeras décadas del siglo. Desde el caso de Pedro Barrenechea -fines de 1830 a comienzos de 1831- destaca la funcionalidad de este tipo de gobiernos, enfatizando que, pese a su conflictividad intrínseca y a su fracaso, no fue inactivo, sino que tuvo múltiples iniciativas en materia fiscal, administrativa, militar y judicial, tendientes a la institucionalización provincial y a erigirse como un gobierno estable.

Ana Romero, en tanto, interpela la idea de orden asociada de manera directa a las presidencias de Julio A. Roca. Para ello, evalúa el conjunto de expectativas previas a su segundo mandato, moduladas por la preocupación ante una posible guerra con Chile por la cuestión limítrofe, la situación económica, y su correlativo impacto en el espacio público. Demuestra que el momento fue leído por los contemporáneos en clave de crisis y no de recuperación del orden. Considera, en este marco, el potencial político que tuvo la movilización impulsada por el patriotismo como respuesta de la ciudadanía, y destaca la actividad de la Liga Patriótica en tanto canal de conexión entre el gobierno y la sociedad movilizada.

Sobre estos lineamientos, lxs autorxs nos informan acerca de los marcos de sentido que entramaron la política. Sara Mata revela la manera en que la crisis abierta por la Independencia concedió a Güemes la oportunidad de nutrir su capital político y simbólico utilizando diversos recursos y atributos propios de su cargo para otorgar promociones, reconocimiento del fuero militar, acceso a la tierra, para cristalizar así una imagen de "protector". El "paternalismo" abonado por Güemes en sus prácticas y retórica muestra vínculos afectivos tejidos entre este y los estratos populares de los ejércitos, lo que reafirma el peso de lo discursivo y de las compensaciones materiales y simbólicas para la obediencia y legitimidad, y dinamiza sus posibilidades 
de acción político-militares. La autora relata, asimismo, cómo esos capitales fortalecieron, pero también condicionaron, su relación con la oficialidad y la elite local.

Pedro Barrenechea también reunía capital simbólico, tanto por ser veterano de lucha revolucionaria y como por su bagaje público en funciones como la Comandancia Militar. Fabián Herrero enfatiza entonces que asumió la gobernación a fines de 1830 con conocimiento del contexto y de la debilidad institucional provincial. El autor nos propone un recorrido por su administración intersectando tres dimensiones: el escenario de crisis que activó "fronteras de actores móviles" en un campo de poder en constante mutación; las múltiples iniciativas institucionales, y, finalmente, la apelación a diversas emociones -injusticia, indiferencia, confianza, valentía, etc.- en una "retórica dramática" que buscó dinamizar y legitimar socialmente dicho proceso de institucionalización provincial y su autoridad. Su capital simbólico y las medidas de gobierno que como apuntaremos también incluyó la articulación a la Liga Federal- no le alcanzaron entonces para imponerse como gobernador propietario, pero estas últimas permanecieron en el repertorio de la política provincial.

Herrero hipotetiza el fracaso de Barrenechea en su imposibilidad de conciliar los diversos sectores, recordándonos, vía Frédéric Lordon, que la acción política es asunto de deseos colectivos y de aspectos cognoscitivos que operan en la vida institucional. En este sentido, Dócola explica la creación de edificios de poder en una didáctica del "buen gusto", según la cual las sensibilidades arquitectónicas son puestas al servicio de la proyección de una moral republicana. Así, se produce a su entender un juego dialéctico entre las mutaciones espaciales y del propio Urquiza en sus sensibilidades. El intento de cimentar un Estado sin Buenos Aires y con ascendente internacional se desdobló en dos “espacios de poder". Por una parte, Urquiza reconvirtió a su residencia "de caudillo" en San José como su ámbito íntimo e identitario de "soberano moderno". Para ello contrató a un arquitecto reconocido como un "fiel federal", que mediante reglas de la antigüedad clásica y ante la potencial condición de capital efímera de Paraná erigió fachadas urbanas simples para los edificios que albergaron los poderes del Estado. Tanto ellos como la casa que Urquiza construyó para visibilizarse también allí se relacionaron con la plaza. La misma se instauró como el centro republicano neurálgico y de "toma de conciencia" de la unidad de la "Confederación". Los representantes provinciales podían integrarse y replicar en sus provincias los principios republicanos y del "buen gusto"; las fiestas con participación popular eran otra parte de las políticas pedagógicas del Estado.

Por su parte, Ana Romero indaga en las intervenciones en la esfera pública que el patriotismo en tanto valor político inspiró en la crítica situación de 1898. Examina así las polémicas en la prensa sobre las iniciativas previas a la elección de Roca, como la compra de un buque de guerra y una suscripción nacional, para focalizar luego en el devenir de la Liga Patriótica. En estas experiencias los actores disputaron lo que implicaba actuar patrióticamente, lo que para Romero se relacionaba con los modos de entender la nación y la identidad, así como lo que era y no legítimo en la intervención pública. El éxito inicial de la Liga radicó en presentarse como una "solución", y se orientó hacia un "patriotismo apolítico" para legitimarse. La movilización que encaró reforzó la preparación bélica, pero también diversos sectores la interpretaban como posible germen disruptivo del orden. Ante la disyuntiva por los acuerdos con Chile de septiembre, la Liga ensayó su propio desarme. De esta manera, Romero concluye que, pese a acompañar las decisiones gubernamentales, colaboró en el clima de insatisfacción que se suscitó un mes después la asunción de Roca. Al mismo tiempo, la práctica de aprendizaje en la movilización permaneció latente y fue capitalizada en otros escenarios de crisis, como el iniciado en 1901.

Por último, interesa destacar que la territorialidad en múltiples escalas y expresiones también opera en los análisis. Entre otras cuestiones, Mata refiere a la amplitud y heterogeneidad del teatro de operaciones militares y políticas que incluía a Salta y su espacio de influencia. Rescata su influjo en aspectos como los márgenes de autonomía, las redes y la capacidad de movilización del espacio rural de los líderes intermedios y en las estrategias de Güemes. Herrero plantea las dificultades de ese espacio “entre ríos”, que dividía a una "misma provincia en dos mitades", con una profusión de comandantes subalternos en Paraná y Concepción 
del Uruguay que complicaban cualquier intento de ocupación efectivo del territorio. Agrega otro elemento, la firma del Pacto Federal en 1831, y la nueva organización que este incluyó. Complejiza así el cuadro vinculado al ejercicio de la autoridad sobre el territorio, destacando los "esfuerzos" en negociar con las restantes provincias y en cooperar con recursos humanos en caso de guerra. Sobre el artículo de Dócola señalamos la interacción entre las apropiaciones territoriales y la construcción identitaria, que también revela polarizaciones internas en la dinámica política de Entre Ríos, en este caso, como sede del gobierno nacional. Por último, Romero inscribe su análisis en el debate global de fin de siglo vertebrado en los conflictos internacionales. El mismo puso en relieve distintas concepciones sobre la nación y la capacidad movilizadora del patriotismo en la política interna, materializada, por ejemplo, en las lecturas de la prensa y en emprendimientos como las Ligas Patrióticas.

Estas notas de conjunto no agotan la riqueza temática y argumental de los artículos, pero fueron organizadas a los fines de presentar las formas en que lxs autorxs nos aproximan a las esferas simbólicas del poder, a las sensibilidades que se despiertan en coyunturas críticas y de cambio. El último dossier del Anuario estuvo dedicado a las emociones. En la Introducción, sus coordinadoras, María Bjergy Sandra Gayol, mencionan que hay consenso historiográfico acerca de que las emociones deben entenderse "enmarcadas históricamente, en un tiempo y espacio concreto", y destacan que "las crisis políticas, económicas y sociales en diferentes partes del globo" colocaron, en los últimos años, en el centro de la escena ciertas emociones. Los trabajos reunidos en este dossier, sin pretensiones de ser análisis sobre ese asunto, advierten acerca de los componentes emocionales de la política y sobre su relevancia para el abordaje de las coyunturas de crisis del siglo XIX, por lo que constituyen, a nuestro juicio, un aporte para una historia política más completa. 